Conclusions: Hypertensive females with rheumatoid arthritis are characterised by higher frequency of insulin resistance, endothelial dysfunction, adiponectin level changes which associates with subclinical atherosclerosis manifestations. Disclosure of Interest: None declared DOI: 10.1136/annrheumdis-2018-eular.2341

\section{FRI0080 THE ROLE OF PAIN IN RHEUMATOID ARTHRITIS (RA) PATIENTS' ASSESSMENTS OF THEIR HEALTH}

P. Katz ${ }^{1}$, Y.C. Lee ${ }^{2}$, A. Quebe ${ }^{3}$, L. Sun ${ }^{3}$, H. Patel ${ }^{3}$, C. Gaich ${ }^{3}$, N. Boytsov ${ }^{3}$, K. Michaud ${ }^{4,5}$. ${ }^{1}$ Medicine, University of California, San Francisco, San Francisco; ${ }^{2}$ Northwestern University, Chicago; ${ }^{3}$ Eli Lilly and Co, Indianapolis; ${ }^{4}$ Forward/NDB, Wichita; ${ }^{5}$ University of Nebraska Medical Center, Omaha, USA

Background: Patients often describe pain as the most important symptom of RA Despite advances in RA therapy to improve disease control, some patients continue to have significant pain ${ }^{1,2}$. The relative impact of pain on RA patients' evaluations of overall health and RA-specific global assessments is unknown.

Objectives: Determine the relative role of pain in RA patients' health assessments.

Methods: Data derived from the Forward (The National Databank for Rheumatic Diseases) longitudinal cohort, collected January-May 2017. Respondents $(n=5471)$ have rheumatologist-confirmed RA. Two health assessments were examined: ${ }^{1}$ overall satisfaction with health (SAT) measured by the item: "How satisfied are you with your health now?" with responses of very unsatisfied to very satisfied; and ${ }^{2}$ patient global assessments of RA impact (GBL) measured using a numeric rating scale (NRS): "Considering all the ways that your RA affects you, rate how you are doing on a scale of $0-10$, where $0=$ very well and $10=$ very poor." For regression analyses, SAT was dichotomized as "very satisfied" or "somewhat satisfied" vs. other responses. Current pain severity was rated on an NRS from 0 (no pain) to 10 (extreme pain). Spearman correlations examined the association of pain with SAT and GBL. Initial multiple regression analyses (table 1, Model 1) examined the following as predictors of SAT and GBL: age, sex, education, disease duration, obesity (BMI $\geq 30$ ), conventional and biologic DMARD use, Rheumatic Disease Comorbidity Index ${ }^{3}(\mathrm{RDCl})$, self-report of depression, fatigue, and functional limitations (Health Assessment Questionnaire [HAQ] score). Follow-up models (Model 2) added pain to determine its relative independent role in health assessments.

Results: The sample was $84 \%$ female, mean age 65 years, mean RA duration 22 years. $53 \%$ were satisfied with their health, and mean GBL was $3.6 \pm 2.5$. Mean pain severity rating was $3.8 \pm 2.8$. Correlations of pain with SAT and GBL were 0.58 and 0.71 , respectively (each $p<0.0001$ ). Regression models predicting both SAT and GBL improved with the addition of pain (table 1). Pain was significantly and independently associated with both health assessments.

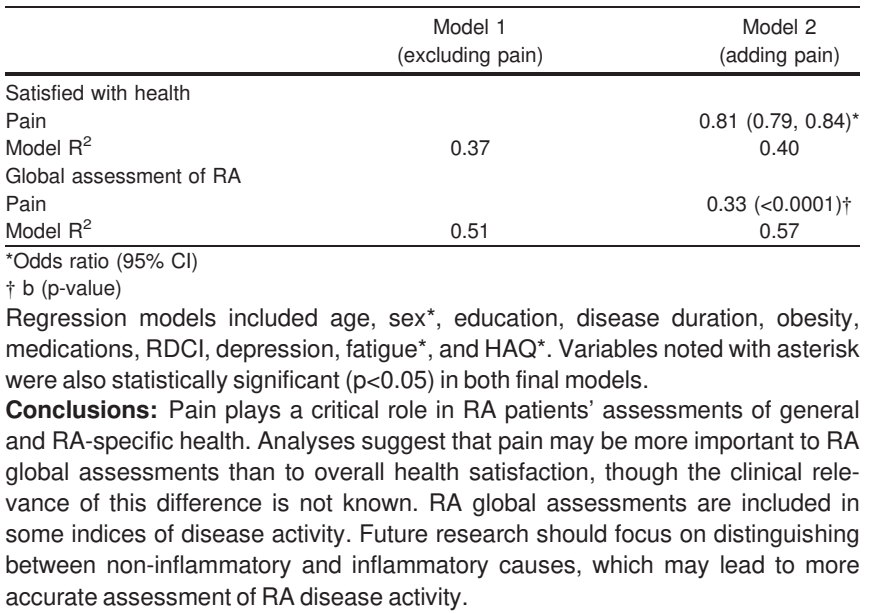

\section{REFERENCES:}

[1] Lee YC, et al. Arthritis Res Ther 2011;13:R83.

[2] Altawil R, et al. Arthritis Care Res 2016;68:1061

[3] England BR. Arthritis Care Res 2015;6:865.

Disclosure of Interest: P. Katz Grant/research support from: Eli Lilly and Co, Y. Lee Grant/research support from: Eli Lilly and Co, A. Quebe Employee of: Eli Lilly and Co, L. Sun Employee of: Eli Lilly and Co, H. Patel Employee of: Eli Lilly and Co, C. Gaich Employee of: Eli Lilly and Co, N. Boytsov Employee of: Eli Lilly and Co, K. Michaud Grant/research support from: Eli Lilly and Co

DOI: 10.1136/annrheumdis-2018-eular.2740

\section{FRI0081 \\ THE IMPORTANCE OF TRANSFERRIN SATURATION, SERUM FERRITIN, LOG FERRITIN AND TRANSFERRIN/ LOG FERRITIN IN DIFFERENTIATING IRON DEFICIENCY ANAEMIA FROM ANAEMIA OF CHRONIC DISEASE IN RHEUMATOID ARTHRITISPATIENTS}

R.A. Abdel Noor ${ }^{1}$, M.H. Abu-Zaid ${ }^{2}$, S.A. Elshweikh ${ }^{3}$, E.S. Rabee ${ }^{4}$, G.E. Khedr ${ }^{5}$ ${ }^{1}$ Internal Medicine and Rheumatology, ${ }^{2}$ Physical medicine, Rheumatology and Rehabilitation; ${ }^{3}$ Internal Medicine and Hematology; ${ }^{4}$ Clinical pathology, Faculty of Medicine, Tanta University; ${ }^{5}$ Clinical pathology, Tanta Cancer Center, Tanta, Egypt

Background: The most common types of anaemia in rheumatoid arthritis (RA) are iron deficiency anaemia (IDA) and anaemia of chronic disease (ACD). The differentiation between both is very important and challenging.

Objectives: is to select the most simple, cheap, accurate method differentiate IDA from ACD in RA patients.

Methods: This case control study was carried out on 80 RA patients. Group I 40 RA patients with anaemia Group II 40 RA patients without anaemia, complete blood count, assessment of disease activity using DAS 28 score, serum iron, tota iron binding capacity (TIBC) "transferrin level", transferrin saturation (TSAT), serum ferritin, log ferritin and transferrin/log ferritin were tested, then we divided the patients in group 1 into 2 subgroups according to TSAT : group la (RA patients with anaemia and low TSAT) and group lb (RA patients with anaemia and normal TSAT) and we compared the parameters.

Results: There was a statistically significant difference between anaemic and non anaemic RA patients as regard serum iron level and transferrin saturation and there was no significant difference as regard serum ferritin, log ferritin, transferrin and transferrin/log ferritin. Among the anaemic group (67.5\%) had low TSAT (IDA) and only (32.5\%) had normal TSAT (ACD). In these 2 subgroups there was no significant differences as regard DAS28 score, blood indices, serum ferritin and transferrin/log ferritin) except Log ferritin and there was positive correlation between TSAT and (ferritin and log ferritin) and significant negative correlation between TSAT and transferrin/log ferritin.

Abstract FRI0081 - Table 1. Clinical and laboratory parameters in both groups

\begin{tabular}{|c|c|c|c|}
\hline Characteristic & $\begin{array}{l}\text { Group } \mathbf{4 0}^{40} \\
\text { RA } \\
\text { +anaemia }\end{array}$ & $\begin{array}{c}\text { Group II } \\
\text { RA without } \\
\text { anaemia }\end{array}$ & $\mathbf{P}$ \\
\hline DAS-28 & $2.99 \pm 1.07$ & $2.35 \pm 0.77$ & $0.002^{*}$ \\
\hline $\mathrm{Hb}(\mathrm{g} / \mathrm{dl})$ & $9.62 \pm 0.96$ & $12.95 \pm 0.64$ & $<0.0001^{*}$ \\
\hline $\operatorname{MCV}(\mathrm{fl})$ & $79.71 \pm 7.29$ & $83.0 \pm 9.34$ & 0.083 \\
\hline MCH (pg/cell) & $26.06 \pm 4.05$ & $28.05 \pm 2.66$ & $0.006^{\star}$ \\
\hline $\mathrm{MCHC}(\mathrm{g} / \mathrm{dl})$ & $31.1 \pm 2.21$ & $31.23 \pm 2.38$ & 0.8 \\
\hline Serum iron $(\mu \mathrm{g} / \mathrm{ml})$ & $0.66 \pm 0.37$ & $0.89 \pm 0.38$ & $0.0076^{*}$ \\
\hline Serum ferritin (ng/ml) & $83.02 \pm 93.08$ & $84.87 \pm 86.82$ & 0.927 \\
\hline TIBC $(\mu \mathrm{g} / \mathrm{ml})$ & $3.94 \pm 1.06$ & $3.71 \pm 0.59$ & 0.23 \\
\hline TSAT (\%) & $17.7 \pm 10.6$ & $24.73 \pm 11.36$ & $0.0054^{*}$ \\
\hline Log ferritin & $1.61 \pm 0.75$ & $1.7 \pm 0.46$ & 0.52 \\
\hline $\begin{array}{l}\text { Transferrin/Log } \\
\text { ferritin }\end{array}$ & $3.23 \pm 3.8$ & $2.41 \pm 0.9$ & 0.18 \\
\hline
\end{tabular}
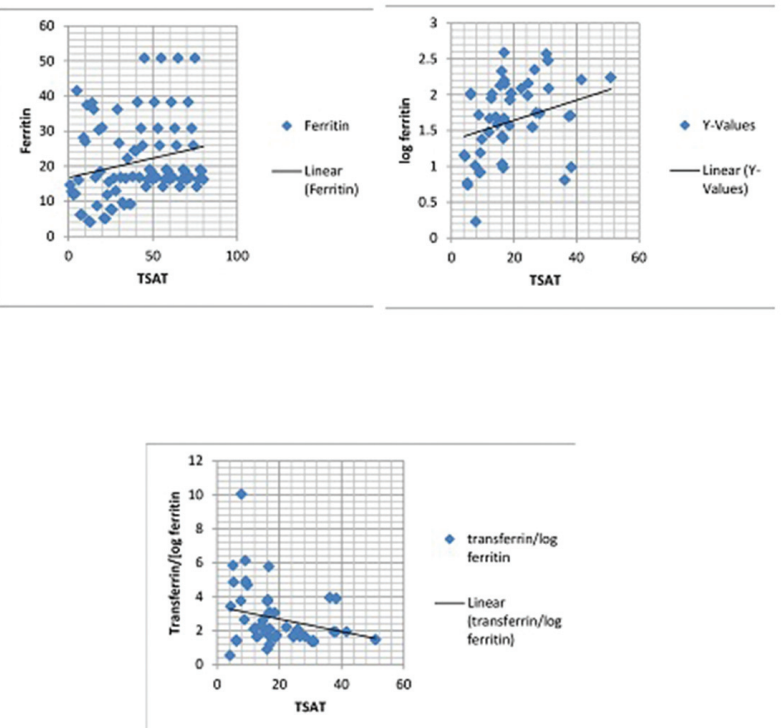

Figure 1 Correlation between TSAT and (serum ferritin, log ferritin and Transferrin/Log ferritin) 
Conclusions: Iron deficiency anaemia is prevalent in RA patients. A combination use of serum ferritin and TSAT is the most simple, accurate parameter now to differentiate both. log ferritin, transferrin/log ferritin may be promising new parameters in diagnosis of IDA in general population but their use in inflammatory diseases like RA still has a limitation so we suggest further large studies to be done in order to assess their accuracy.

\section{REFERENCES:}

[1] Song J-S, Park W, Bae S-K, Kim S-S, Lee Y-H, Choi J-W, et al. The usefulness of serum transferrin receptor and ferritin for assessing anemia in rheumatoid arthritis: comparison with bone marrow iron study. Rheumatology International 2001;21(1):24-9.

[2] Castel R, Tax MG, Droogendijk J, Leers MP, Beukers R, Levin M-D, et al. The transferrin/log (ferritin) ratio: a new tool for the diagnosis of iron deficiency anemia. Clinical Chemistry and Laboratory Medicine 2012;50 (8):1343-9.

Disclosure of Interest: None declared DOI: 10.1136/annrheumdis-2018-eular.3969

\section{FRI0082 PREDICTORS OF FATIGUE AND PERSISTENT FATIGUE IN EARLY RHEUMATOID ARTHRITIS: A LONGITUDINAL OBSERVATIONAL STUDY}

S. Rodríguez-Muguruza ${ }^{1}$, B. Combe ${ }^{2}$, F. Guillemin $^{3,4}$, B. Fautrel $^{5}$, A. Olive $^{6}$, S. Marsal ${ }^{7}$, O. Valero ${ }^{8}$, N. Rincheval ${ }^{9}$, C. Lukas ${ }^{2} .{ }^{1}$ Rheumatology, Verge de la Cinta Hospital, Tarragona, Spain, ${ }^{2}$ Rheumatology, CHU Montpellier, Montpellier University, Montpellier, ${ }^{3}$ Université de Lorraine, EA 4360 APEMAC, École de Santé Publique, Faculté de Médecine de Nancy; ${ }^{4}$ INSERM CIC 1433 clinical epidemiology, Nancy Hospital, Nancy, ${ }^{5}$ Rheumatology, Pitié-Salpêtrière hospital, AP-HP, 75013, Paris, France; ${ }^{6}$ Rheumatology, Germans Trias i Pujol University Hospital; ${ }^{7}$ Rheumatology, Vall d'Hebrón Hospital; ${ }^{8}$ Senvei d'estadística aplicada, Universitat Autonoma de Barcelona, Barcelona, Spain; ${ }^{9}$ UFR de Médecine, Institut Universitaire de Recherche Clinique, Université Montpellier 1, Montpellier, France

Background: Fatigue is a multifactorial and persistent symptom reported by patients with rheumatoid arthritis (RA). It is considered as frequent as pain. It would be of value to identify potential predictive factors of fatigue that can influence on its evolution.

Objectives: To identify predictive factors of fatigue and of persistent fatigue in a large prospective cohort of early RA patients.

Methods: The Etude et Suivi des polyarthrites Indifferenciees Récentes (ESPOIR) is a multicenter French cohort of patients with early arthritis. We selected patients fulfilling the 2010 ACR/EULAR criteria for RA during the first year of follow-up. We recorded sociodemographic and clinical characteristics, the SF-36 vitality score, Health Assessment Questionnaire (HAQ) score and 28-joint Disease Activity Score (DAS28) at baseline and every 6 months up to 5 years. The association of fatigue (SF vitality score $\leq 40$ ) or persistent fatigue (SF vitality score $\leq 40$ at the end of the study and at least in $50 \%$ of visits in the 5 years follow up) with other characteristics were evaluated by bivariate logistic regression models/tests (chi-squared test for qualitative variables and t-test/Mann-Whitney test for quantitative variables). A multivariate logistic regression model was used to determine independent predictors of persistent fatigue.

Results: We included 677 patients $(73.4 \%$ women, mean \pm SD age $48.6 \pm 12$ years); $46.5 \%, 28 \%$ and $22 \%$ of RA patients presented fatigue at baseline, 6 months and 5 years of follow up respectively. At baseline, fatigue was independently and significantly associated with single patients $(\mathrm{OR}=2.595 \% \mathrm{Cl}[0.30-$ $0.70] \mathrm{p}<0.001)$, higher $\mathrm{BMI}(\mathrm{OR}=1.195 \% \mathrm{Cl}[1.01-1.10] \mathrm{p}=0.007)$, higher DAS28 $(\mathrm{OR}=1.395 \% \mathrm{Cl}[1.08-1.60] \mathrm{p}=0.006)$, higher severity of morning stiffness (scored 0-10) $(\mathrm{OR}=1.095 \% \mathrm{Cl}[1.00-1.01] \mathrm{p}=0.012)$, higher $\mathrm{HAQ}(\mathrm{OR}=2.4$ $95 \% \mathrm{Cl}[1.70-3.44] \mathrm{p}<0.001)$, negativity of $\mathrm{FR}(\mathrm{OR}=1.595 \% \mathrm{Cl}[1.09-2.29]$ $\mathrm{p}=0.016)$ and history of depression or anxiety $(\mathrm{OR}=6.195 \% \mathrm{Cl}[3.90-$ 9.83] $\mathrm{p}<0.001)$. A $14.9 \%$ of patients presented persistent fatigue. Independent predictors of persistent fatigue at 5 years of follow-up were $\mathrm{HAQ}(\mathrm{OR}=2.595 \% \mathrm{Cl}$ [1.63-3.67] $\mathrm{p}<0.001)$, history of depression/anxiety (OR=3.7 95\% Cl [1.53-9.15] $\mathrm{p}=0.004),>3$ comorbidity $(\mathrm{OR}=2.195 \% \mathrm{Cl}[1.23-3.73] \mathrm{p}=0.007)$, dry syndrome $(\mathrm{OR}=2.495 \% \mathrm{Cl}[1.39-4.17] \mathrm{p}=0.002)$, and negativity in $\mathrm{RF}(\mathrm{OR}=1.8595 \% \mathrm{Cl}$ [1.07-3.21] $\mathrm{p}=0.027)$.

Conclusions: Fatigue was frequent in this cohort of early RA patient, its presence decreased at 6 months and remained stable over time. Baseline fatigue and persistent fatigue were both predicted by functional impairment, negativity of RF and history of depression or anxiety. Disease activity measured by DAS28 was strongly associated to fatigue at baseline but it was not a predictor of persistent fatigue.

Disclosure of Interest: None declared

DOI: 10.1136/annrheumdis-2018-eular.2648

\section{FRI0083 \\ ADJUSTMENT OF THE THRESHOLD MAY IMPROVE CARDIOVASCULAR RISK STRATIFICATION IN PATIENTS WITH RHEUMATOID ARTHRITIS}

S. Velmakin, E. Troitskaya, S. Villevalde, Z. Kobalava. Internal diseases, Peoples` Friendship University of Russia (RUDN University), Moscow, Russian Federation

Background: Rheumatoid arthritis (RA) is associated with increased cardiovascular (CV) risk. Besides monitoring of the disease activity, identification of high CV risk patients is of great importance ${ }^{1,2}$.

Objectives: The aim of the study was to assess the abilities of 3 risk models (SCORE, QRisk 2 and 10 year ASCVD) in detecting high CV risk RA patients.

Methods: 56 patients with RA (ACR/ ${ }^{\text {EULAR } 2010}$ without known CV disease were examined ( $84 \%$ females, age $58.4 \pm 14.1$ (M $\pm S D$ ) years, BMl $26.1 \pm 5.4 \mathrm{~kg} / \mathrm{m}^{2}$, smokers $9 \%$, arterial hypertension $(\mathrm{AH}) 64 \%$, dyslipidemia $57 \%$, diabetes $7 \%$ ). Median duration of RA was 7 years (IQR 2-14). Seropositive RA was diagnosed in $73 \%$ of patients. Median hsCRP was $7.8 \mathrm{mg} / \mathrm{dl}$ (IQR 2;21.4), rheumatoid factor (RF) - 61.2 IU/ml (IQR 18.5;179.2), mean DAS-28(CRP) - 3,7 $\pm 1,2$. All patients received disease-modifying antirheumatic drugs. SCORE, QRisk2 and 2013 ACC/AHA 10 year ASCVD risk and EULAR recommended modified versions were calculated. Patients with SCORE $\geq 5 \%$, QRisk2 $\geq 20 \%$ and ASCVD risk $\geq 7.5 \%$ were classified as having high $\mathrm{CV}$ risk. Carotid intima-media thickness $(\mathrm{CIMT})>0,9 \mathrm{~mm}$ and/or carotid plaques detected by ultrasonography were used as the gold standard test for high $\mathrm{CV}$ risk. $\mathrm{p}<0.05$ was considered significant. Results: The median SCORE, QRisk2 and ASCVD were 2.2\% (IQR 0.6;4.9), $10.2 \%(3.4 ; 19.2)$ and $4.9 \%(1.5 ; 12.8)$ respectively. The proportion of high-risk patients was as follows: $14(25 \%), 13(23 \%), 24$ (43\%) for SCORE, QRisk2 and ASCVD. Mean CIMT was $0.76 \pm 0.24 \mathrm{~mm}$. US criteria for subclinical atherosclerosis (US+) were found in 27 (48\%) pts. Discriminating capacities for the indexes were as follows: AUC $0.723(\mathrm{Cl} 95 \%$ 0.626-0.821) for SCORE, AUC $0.705(\mathrm{Cl}$ 95\% 0.606-0.804) for QRisk2 and AUC 0.837 (CI 95\% 0.757-0.917) for ASCVD. The percentages of high-risk patients in US+group were as follows: 13 (48\%), 12 (44\%) and 21 (78\%), respectively, ( $p<0.05$ compared to ASCVD). After multiplying by 1.5 EULAR 2016 mASCVD reclassified $2(7.4 \%)$ and mSCORE - $4(14.8 \%)$ pts from moderate to high risk. Use of lower cut-off values for risk indices (SCORE $\geq 1 \%$, QRisk2 $\geq 10 \%$ and ASCVD $\geq 5 \%$ ) resulted in better detection of US+pts (100\%, $85 \%$ and $85 \%$ respectively).

Conclusions: The 2013 ACC/AHA 10 year ASCVD risk estimator is better than the SCORE and QRisk2 indices for the detection of high CV risk RA patients. Adjustment of the threshold may be a better modification of risk scales than use of the EULAR multiplier factor.

\section{REFERENCES :}

[1] Agca R, Heslinga S, Rollefstad S, et al. EULAR recommendations for cardiovascular disease risk management in patients with rheumatoid arthritis and other forms of inflammatory joint disorders: 2015/2016 update. Ann Rheum Dis 2017;76(1):17-28.

[2] Avina-Zubieta JA, Thomas J, Sadatsafavi M, Lehman AJ, Lacaille D. Risk of incident cardiovascular events in pa- tients with rheumatoid arthritis: a meta-analysis of obser- vational studies. Ann Rheum Dis 2012;71:1524-9.

Disclosure of Interest: None declared

DOI: 10.1136/annrheumdis-2018-eular.4381

\section{FRI0084 INTENSE AEROBIC AND RESISTANCE EXERCISE REDUCES THE FREQUENCY OF PERIPHERAL BLOOD REGULATORY CELL POPULATIONS IN ELDERLY PATIENTS WITH RHEUMATOID ARTHRITIS}

S. Andersson ${ }^{1}$, E. Lange ${ }^{2}$, D. Kucherski ${ }^{1}$, S. Svedlund ${ }^{3}$, K. Önnheim ${ }^{1}$, J. Lord ${ }^{4}$, I.L. Mårtensson ${ }^{1}$, K. Mannerkorpi ${ }^{2}$, I. Gjertsson ${ }^{1} .{ }^{1}$ Dept of Rheumatology and Inflammation Research; ${ }^{2}$ Department of Health and Rehabilitation; ${ }^{3}$ Department of Molecular and Clinical Medicine, University of Gothenburg, Göteborg, Sweden; ${ }^{4}$ Institute of Inflammation and Ageing, University of Birmingham, Birmingham, UK

Background: RA is an autoimmune joint disease driven by complex immune dys regulation. Exercise can improve immune health and is beneficial for physica function in elderly patients with RA, but the immunological mechanisms are largely unknown.

Objectives: We evaluated the effect of a person-centred randomised controlled exercise programme on regulatory immune cell populations in aged persons with RA.

Methods: Aged persons with RA were randomised to either a 20 week of aerobic and resistance exercise intervention of moderate-to high intensity $(n=24)$ or to an active control group performing low-intensity home exercise $(n=25)$. Blood samples were collected at baseline and after 20 weeks. The frequency of the adaptive regulatory populations Foxp3 +CD25+CD127 CD4+T cells and CD24hiCD38hi B 